\title{
Narrativas deleitosas de la nación. Los primeros libros de cocina en México (1830-1890)*
}

\author{
Sarah Bak-Geller Corona
}

\begin{abstract}
El presente artículo analiza los primeros libros de recetas mexicanas (I830-|890) y su papel en la creación de una identidad nacional. Tres aspectos permiten considerar a los primeros recetarios mexicanos como uno de los proyectos más audaces e innovadores en la construcción de la idea de "mexicanidad": en primer lugar, la valorización de los productos nativos del país; en segundo, la legitimación del español vernáculo y la implementación de un lenguaje culinario nacional y, por último, la emergencia de una nueva manera de concebir el tiempo histórico a partir de la apropiación y la reinvención de prácticas culinarias prehispánicas.
\end{abstract}

PALABRAS CLAVE: nacionalismo, discurso culinario, siglo XIX, libros de cocina, identidad

Delectable Narratives of the Nation. The First Mexican Cookbooks (1830-1890)

This paper analyzes the role of Mexico's first cookbooks (1830-1890) in the creation of a national identity. Three aspects allow us to consider these cookbooks as a genuine and novel political project in the building of the idea of mexicanidad. In the first place, valorization of local ingredients; secondly, legitimization of vernacular Spanish and implementation of a national culinary language; finally, the emergence of a new understanding of historical time throughout the appropriation and reinvention of prehispanic cuisines.

KEYWORDS: nationalism, culinary discourse, $19^{\text {th }}$ century, cookbooks, identity

Sarah BaK-Geller Corona: Centro de Investigaciones y Estudios Superiores en Antropología Social-Distrito Federal bakgeller@gmail.com

Desacatos, núm. 43, septiembre-diciembre 2013, pp. 31-44

Recepción: 8 de marzo de 2012 / Aceptación: 12 de abril de 2013

\footnotetext{
*Agradezco los comentarios de Eva Salgado Andrade y de los dictaminadores anónimos para la versión final de este texto.
} 
$\mathrm{L}$ a cocina mexicana se concibe en general como el producto de cinco siglos de historia. Desde esta perspectiva, el encuentro entre aztecas y españoles es identificado como el momento fundacional de una cocina que se ha desarrollado de manera lineal e ininterrumpida. ${ }^{1}$ En los últimos años, la idea de una cocina mexicana única, ancestral y auténtica ha sido cuestionada en los debates historiográficos sobre cocina en México, lo que plantea la necesidad de estudiar la dimensión fabricada e "imaginada" de la cocina nacional (Pilcher, 2000, 2001; Cardon y García-Garza, 2012). Estos trabajos formulan nuevas interrogantes sobre los orígenes y el significado social de la cocina mexicana e incursionan en el estudio de fuentes poco atendidas por la historiografía nacional, en particular, los libros de cocina. ${ }^{2}$ No obstante, en esta renovada perspectiva histórica de los estudios sobre cocina en México los conceptos de nación, nacionalismo y modernidad carecen de una reflexión crítica y con frecuencia son empleados como nociones preestablecidas $y$ teleológicas (Juárez, 2012). ${ }^{3}$ Sin una problematización previa del fenómeno mismo del nacionalismo, la nación se impone en estos trabajos como un concepto categórico y definido a priori, que impide considerar

\footnotetext{
${ }^{1}$ En los últimos años, la idea de una cocina nacional ancestral y única ha sido reforzada por el gobierno y por un grupo de promotores culturales mexicanos que lograron que en 2010 la Organización de las Naciones Unidas para la Educación, la Ciencia y la Cultura (UNESCO) la nombrara "patrimonio inmaterial de la humanidad". Los argumentos expuestos en la candidatura subrayan sus orígenes prehispánicos e insisten en su significado identitario en tanto "poderoso factor de cohesión social e identidad nacional” (UNESCO, 2010).

${ }^{2}$ Un trabajo pionero sobre la dimensión nacionalista de los recetarios es la investigación sobre libros de cocina en India de Appadurai (1988). En general, la bibliografía sobre cultura nacional en México pasa por alto el fenómeno de la cocina y su importancia como producto y productor de sentido nacional (Florescano, 1991; Noriega, 1992; Blancarte, 1994; Lomnitz, 2001).

${ }^{3}$ Este autor incurre en errores históricos y en una falsa problematización del fenómeno nacional respecto de la cocina mexicana, que consiste en la ausencia de distancia frente al discurso nacional y en sus criterios de legitimidad basados en los principios de unidad y representación reproducidos de manera acrítica.
}

el discurso culinario como un elemento constitutivo en la construcción del sentido nacional.

En este artículo proponemos estudiar los discursos sobre la cocina como una de las primeras manifestaciones de la idea de nación, puesto que representan una dimensión fundamental en la construcción del Estado-nación y del imaginario nacional en México. ${ }^{4}$ Para desarrollar nuestro argumento, analizaremos los contenidos de los primeros libros de cocina y nos enfocaremos en tres aspectos que hacen de estos impresos unos de los documentos forjadores del sentido nacional: ${ }^{5}$ la creación de un repertorio de ingredientes y platillos "nacionales", la articulación de un nuevo lenguaje culinario referido a la idea de la nueva nación y la introducción de un pasado histórico que proporciona a la nación una dimensión de autenticidad y tradición.

\section{LA INVENCIÓN DE UN GÉNERO EDITORIAL: EL RECETARIO NACIONAL}

Los orígenes del recetario impreso en Occidente datan de 1470 con la publicación en Roma del De Honesta Voluptate, escrito por Bartolomeo Platina (Willian, 2012). Desde entonces aparecieron recetarios en casi todas las lenguas vernáculas de Europa. Entre 1485 y 1695 se imprimieron recetarios en alemán, francés, holandés, catalán, español, checo, polaco, danés, sueco, portugués y húngaro (Laurioux, 1997; Simon, 1977). Los autores de estos primeros recetarios fueron en su mayoría

\footnotetext{
${ }^{4}$ El periodo que estudiamos, de 1830 a 1890 , se caracteriza por la coherencia del discurso culinario nacional en términos de contenido, implicaciones e impacto en la esfera política, social y culinaria. Más adelante, la aparición de un nuevo repertorio culinario, el desarrollo de políticas asimilacionistas dirigidas a la población indígena, la preponderancia del discurso higienista, la introducción de comidas escolares y la proyección internacional de la cocina mexicana, entre otros aspectos, inaugurarán una nueva etapa en la historia del nacionalismo culinario en México.

${ }^{5}$ Para una discusión sobre los recursos textuales en la formación de la nación, véanse en particular Bhabha (1990), Hartog y Revel (2001) y Palti (2002).
} 
cocineros al servicio de las elites aristocráticas y eclesiásticas, quienes vieron en la imprenta una oportunidad para difundir su celebridad entre la nobleza europea y la burguesía en ascenso. Durante la Ilustración, las políticas editoriales de difusión de los saberes científicos y técnicos impulsaron la publicación de recetarios en ediciones económicas dirigidas al público en general (Girard, 1977; Toussaint-Samat, 2001). A inicios del siglo XIX, el mercado europeo contaba con dos modelos de recetarios: uno destinado a cocineros profesionales en los que se exhibía una cocina de lujo y abundancia, y otro que introducía la noción de cocina "burguesa", es decir, de confección doméstica y basada en el ahorro y la simplicidad.

Si bien es más reciente, la historia de los recetarios impresos en Hispanoamérica posee particularidades que merecen atención. Los autores y editores de estos primeros libros de cocina combinaron elementos de los dos modelos europeos de recetarios y los adaptaron a una clase social en construcción, por un lado, deseosa de aparentar una mesa de lujo y abundancia y, por otro, interesada en evitar los desperdicios y aprovechar las sobras. Sin embargo, la característica principal de los recetarios hispanoamericanos es que desde un inicio contienen una impronta patriótica. Entre 1831, fecha de la publicación del Cocinero mexicano, y finales del siglo xIx, la mayoría de las nuevas repúblicas hispanoamericanas contaron con sus propios recetarios, concebidos a partir de la idea de una cocina única, original, anclada en antiguas tradiciones y diferente a cualquier otra en el continente y en el resto del mundo. Dos casos evocadores del inminente sentido patriótico de los primeros recetarios hispanoamericanos son Cuba y Puerto Rico: sus libros de cocina fueron publicados en 1858 y 1859 , respectivamente, cuando ninguno de los dos territorios se había constituido aún como nación independiente.

El antecedente más antiguo del recetario nacional hispanoamericano es el American Cookery, escrito por Amelia Simmons en Hartford, Connecticut, y publicado en 1796. En su pequeño y breve recetario,
Simmons establecía una distinción entre el gusto de sus compatriotas estadounidenses y el de los ingleses. Simmons había adaptado las recetas inglesas a los ingredientes del Nuevo Mundo, de modo que los platillos pudieran ser confeccionados por la mayoría de las cocineras del país. Por ejemplo, el American Cookery sugiere sustituir la avena por el maíz y propone recetas a base de pavo - un ave originaria de América del Norte-, de la calabaza nativa del país - squash - y de otros ingredientes locales. ${ }^{6}$ Asimismo, Simmons inventó para sus novedosas recetas sugerentes y patrióticos títulos que mostraban el clima político luego de la guerra de la independencia en Estados Unidos, como "Election Cake", "Independence Cake" y "Federal Pan Cake".

En México, la publicación de los primeros recetarios data de $1831^{7}$ e inaugura un nuevo género editorial en América Latina. ${ }^{8}$ El cocinero mexicano, el Novísimo arte de cocina [...] para sazonar al estilo de

\footnotetext{
${ }^{6}$ La harina de maíz es celebrada por la misma Simmons como una especificidad de la nación estadounidense: por una parte, rompía con la costumbre propia de los indios nativos de cocer el maíz y, por otra, se distinguía de la de los primeros migrantes europeos y africanos que empleaban el cereal en forma de grano o masa: "Si bien el maíz ha sido utilizado por los nativos americanos desde hace varios milenios, así como por los primeros inmigrantes europeos y africanos, este libro ofrece las primeras recetas impresas que emplean harina de maíz" ["Although native Americans had been using corn for many millennia, and European and African Americans from earliest pilgrim days, this book offers the first printed recipes using cornmeal'] (Simmons, 1796). A diferencia de la harina de maíz empleada en México, la que Simmons utiliza en sus recetas se mezcla con un agente químico que sirve de levadura y que es el precursor del polvo de hornear -baking powder-.

${ }^{7}$ Muriel y Pérez (2003: 472) aluden a un recetario impreso en Nueva York en 1828: Arte nuevo de cocina y repostería. Acomodado al uso mexicano. Asimismo, el prólogo de la primera edición del Cocinero mexicano (1831) hace referencia - sin nombrar el título- a un recetario previamente publicado, no obstante, desconocemos el paradero de estos ejemplares.

${ }^{8}$ Le siguen los primeros tratados de cocina cubana y puertorriqueña - Manual de repostería, pastelería, confitería y licorista de la cocinera catalana y del cocinero cubano (1858) y Cocinero puertoriqueño o formulario para confeccionar toda clase de alimentos, dulces y pasteles (1859)—, de Chile - El cocinero chileno (1867)-, de Perú - La mesa peruana (1867) — y de Argentina - La cocina argentina (1887), Cocina ecléctica (1890)—.
} 
nuestro país y el Nuevo y sencillo arte de cocina, repostería y refrescos dispuesto por una mexicana fueron impresos en las mejores prensas de la capital y distribuidos en las principales ciudades del país. Del mismo modo que el American Cookery, los primeros recetarios mexicanos estuvieron insertos en un contexto de reciente descolonización y de búsqueda de referentes nacionales. No obstante, los recetarios mexicanos, a diferencia del libro de Simmons, fueron concebidos por ambiciosos editores cuyos horizontes comerciales permitieron que los ejemplares tuvieran una considerable circulación. ${ }^{9}$ No debe desdeñarse tampoco que los forjadores de este nuevo género editorial fueran editores que no sólo buscaban difundir nuevas fórmulas de cocina, sino que también estaban comprometidos con una causa nacional atravesada por un problema crucial: la construcción del sentido mismo de "mexicanidad". Mariano Galván, editor del Cocinero mexicano, fue uno de los fundadores del Instituto de Geografía y Estadística y el responsable, entre muchos otros proyectos patrióti-

cos, de la edición e impresión de la Constitución de los Estados Unidos de Norteamérica y de una colección de constituciones para cada estado de la República Mexicana (Solares, 2003). Por su parte, Alejandro Valdés, editor de Novísimo arte de cocina, hizo imprimir las Actas del Congreso Constitucional de 1824.

En Europa, los recetarios nacionales aparecen tardíamente, recién en la segunda mitad del siglo XIX, y carecen de la originalidad y los alcances que caracterizan a los primeros libros de cocina

\footnotetext{
${ }^{9}$ En el "Prospecto" de una edición posterior del primer Cocinero mexicano el editor aclara: "Tres mil ejemplares consumidos en poco tiempo de las dos ediciones del Cocinero mejicano, sin que pudiesen obstruir su venta las innumerables que tanto en castellano como en francés nos han venido del extranjero; el subido precio a que se paga el ejemplar de aquélla, que por casualidad se encuentra, y los frecuentes pedidos que se hacen tanto de la capital como de los Departamentos, son una prueba irrefragable de aquella verdad, y lo son al mismo tiempo del aprecio con que la ha acogido el público" (Nuevo cocinero mexicano, 1888). Para un análisis más detallado sobre la circulación de estos recetarios, véase Bak-Geller (2008).
}

hispanoamericanos. ${ }^{10}$ En Italia, no será sino hasta 1891, medio siglo después de que el editor mexicano Mariano Galván imprimiera su Cocinero mexicano, que Pellegrino Artusi publicara su Scienza in Cucina, el primer recetario italiano que reúne las cocinas de todas las regiones del país. A pesar de tratarse de un modelo reputado en el arte de la gastronomía, lo mismo sucede con el caso francés. ${ }^{11}$ Los célebres recetarios de Antoine Carême, publicados en 1810 y en 1828 respectivamente, son ajenos a cualquier reivindicación nacionalista. Por el contrario, al igual que los ideales de la Revolución Francesa, promueven la cocina del país como un arte "universal". Habrá que esperar hasta principios del siglo xx para que los recetarios franceses asocien los valores universalistas de la cocina francesa a la imagen de una nación moderna. ${ }^{12}$ Así, los libros de cocina mexicana, en comparación con los principales recetarios nacionales en Occidente, constituyen la vanguardia en este género editorial.

La temprana implementación de un canon culinario nacional en México (1831) es más significativa si se considera que las nociones de "México" y "mexicano" eran empleadas de manera poco habitual en los discursos políticos de aquellos años - la primera Constitución Federal de los Estados Unidos Mexicanos, documento fundador de la idea de Estado-nación moderno, había sido decretada en

\footnotetext{
${ }^{10}$ Entre los primeros recetarios nacionales en Europa podemos citar los tratados de cocina griega (1828) y noruega (1831). El primero, sin embargo, se limita a traducir recetas francesas e italianas para luego hacerlas pasar por griegas, mientras que el segundo es una copia de un libro de origen danés. Para un recuento general de los recetarios europeos decimonónicos, veáse Notaker (2002: 137-150).

${ }^{11}$ El reconocimiento de una "cocina nacional" francesa estuvo generalmente a cargo de paladares extranjeros. Por ejemplo, Goethe, durante su paso por la Lorena, en 1792, apreció un sabroso caldo que no dudó en denominarlo como "el famoso puchero nacional" - le fameux pot-au-feu nacional- (Goethe, La Campagne de France, citado en Carantino, 1999: 35).

${ }^{12}$ No es sino hasta 1926 que un recetario francés identifica por primera vez el platillo habitual del país, el pot-au-feu, como "nuestro pot-au-feu francés". Se trataba de uno de los recetarios más populares de la época: La Cuisine de madame Saint-Ange.
} 


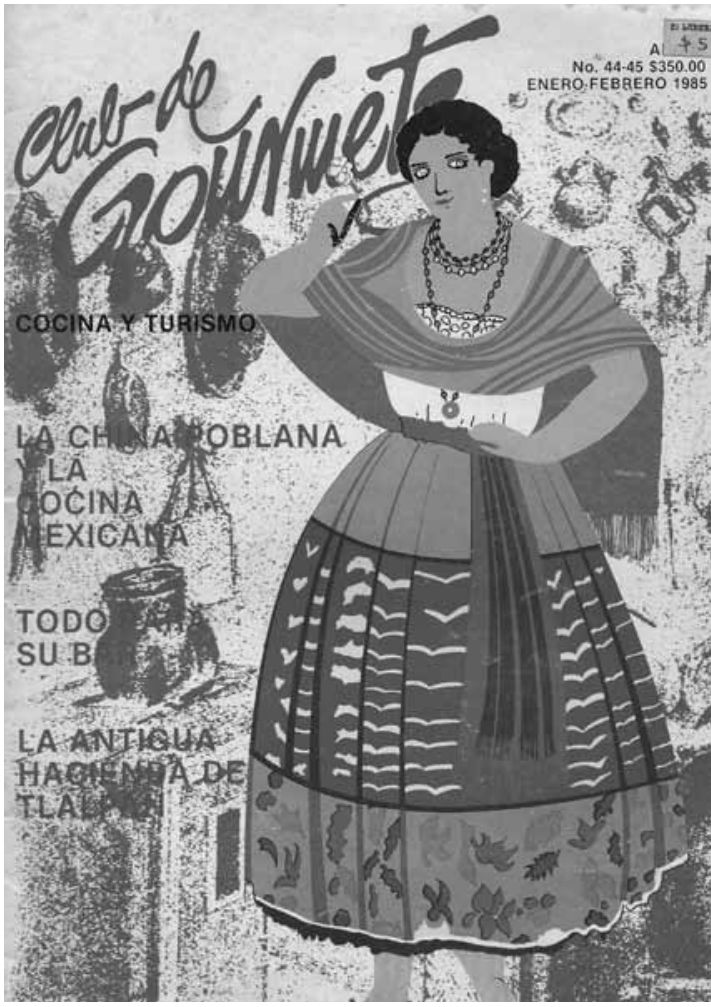

Revista Club de Gourmet, enero-febrero de 1985. La cocina comparte el campo semántico de la "mexicanidad" con otros iconos estéticos de la nacionalidad: la China Poblana y las haciendas.

1824, apenas siete años antes de la publicación de los primeros recetarios mexicanos-. Si tomamos en cuenta las expresiones más celebradas de la cultura nacional, como la fundación de la Academia de Letrán y su programa de "mexicanización" de las letras (1836), el himno patrio (1854), la organización de un Museo Nacional (década de 1870) y el primer compendio de historia nacional (1884-1889), ${ }^{13}$ por citar algunos ejemplos, sobresale el hecho de que todas ellas fueron posteriores a la impresión de $E l$ cocinero mexicano.

La publicación de los recetarios mexicanos representó una verdadera coyuntura en el proceso de construcción nacional. A través de una selección de recetas

\footnotetext{
${ }^{13}$ México a través de los siglos, obra en cinco tomos dirigida por Vicente Riva Palacio.
}

conocidas sobre todo por la población del centro del país ${ }^{14}$ los editores de los libros de cocina forjaron una imagen particular de la nación mexicana que ha resultado ser una de las más consistentes y duraderas expresiones de nacionalidad hasta la actualidad. Como hemos indicado, tres aspectos predominantes en los primeros recetarios mexicanos proporcionan pistas para comprender cómo se llevó a cabo el exitoso proceso de mexicanización desde la cocina. En primer lugar, la tipificación de ingredientes y platillos locales y la creación de un repertorio culinario nacional; en segundo lugar, la legitimación del español vernáculo y la implementación de un vocabulario culinario nacional; por último, la emergencia de una nueva temporalidad histórica a través de la apropiación y reinvención de cocinas precoloniales.

\section{INGREDIENTES DE LA MEXICANIDAD}

La característica principal de la narrativa culinaria mexicana es la importancia que los autores de los recetarios otorgan a los ingredientes locales y a los platillos del país. Esta valorización de los productos nativos, lejos de ser una novedad, había sido introducida por la retórica americanista de los criollos de la Nueva España desde fines del siglo XVI y alcanzó su mayor visibilidad durante el siglo XVIII. La discusión novohispana sobre las cualidades del maíz, el chile, el frijol, el pulque, los atoles y otros alimentos comunes en la dieta del virreinato formaba parte de un debate científico en el que eruditos criollos y europeos confrontaron sus teorías acerca de los atributos geográficos, naturales y morales del Continente Americano y sus habitantes. Naturalistas prestigiados como Georges-Louis Leclerc Buffon, Cornelius de Paw y Guillaume-Thomas François Raynal sostenían que la mala calidad del clima, el aire y el suelo

${ }^{14}$ Un interesante estudio desde la perspectiva yucateca acerca del problema de la representatividad del discurso culinario nacional decimonónico se encuentra en Ayora-Díaz(2012). 


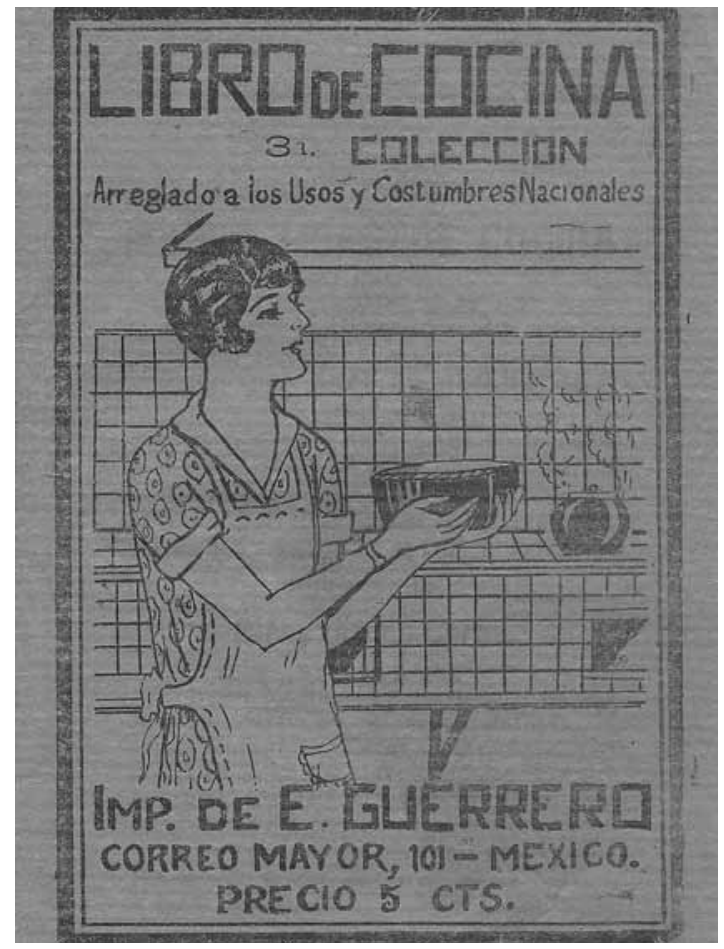

Libro de cocina arreglado a los usos y costumbres nacionales, ca. 1920, México. Modesto folleto que apuesta por una representación modernizadora de la cocina nacional, reflejada en el espacio ordenado y aséptico, desprovisto de fogones y equipado con utensilios aparentemente de manufactura industrial.

de América corrompían todas las manifestaciones de la naturaleza en el continente y producían hombres degenerados y viciados en estas regiones del mundo (Hume, 1742; Leclerc, 1749-1788; De Pauw, 1768; Raynal, 1770). En este registro, los eruditos describían los alimentos del Nuevo Mundo como escasos y malsanos, idea que llegaron a vincular con los sacrificios humanos realizados por los mexicas, que explicaban como impulsos caníbales de un pueblo que no tenía nada mejor que comer (Voltaire, 1994: cap. XIV; Camporesi, 1981: 43).

La distinción entre los españoles que nacían en Europa y aquellos que nacían en América no era por tanto étnica, cultural ni social, sino esencialmente geográfica. El privilegio del suelo se imponía al de la sangre, de modo que los criollos, por el hecho de haber nacido en las Indias, eran confinados en la jerarquía del poder colonial a una posición de inferioridad respecto de sus antecesores nacidos en el Viejo Mundo. Por su parte, no es sorprendente que los criollos, conocedores de esta discusión, se hayan apropiado de los presupuestos naturalistas europeos que justificaban la "excepcionalidad" americana y que los hayan modificado a su favor. ${ }^{15}$ Así, desarrollaron un contradiscurso geográfico y naturalista que exaltaba la diversidad, el vigor y la opulencia de la naturaleza americana, ${ }^{16}$ en el que la reivindicación de la comida americana frente a los ilustrados europeos fue crucial. ${ }^{17}$

Los autores de los primeros recetarios mexicanos recuperaron el debate colonial y antiamericano, con lo que transformaron la querella dieciochesca en una oportunidad para elaborar un discurso sobre las riquezas culinarias de la nación mexicana. Si bien los términos que emplean los autores de los recetarios para exaltar los productos del país son similares a los utilizados por los ilustrados novohispanos de la segunda mitad del siglo XVIII, ${ }^{18}$ el discurso americanista adquiere una nueva dimensión

\footnotetext{
${ }^{15}$ Sobre la noción de excepcionalidad e inferioridad geográfica de los continentes no europeos como principio que legitimó el sistema colonial, véase la discusión de Partha Chatterjee en torno a su concepto de "rule of colonial difference" (Chatterjee, 1993: 18). Entre los autores que han estudiado la importancia de los saberes geográficos y de las ciencias naturales como factores decisivos de las reivindicaciones "criollas" deben mencionarse el libro de Antonello Gerbi (1982) y los trabajos de Bernard Lavallé et al. (1991).

${ }^{16} \mathrm{El}$ mismo Alexander von Humboldt se sorprendió al descubrir la enorme producción científica realizada por los criollos acerca de la fauna, la flora y los minerales americanos, la cual aprovechó para redactar a partir de ella su propia obra (von Humboldt, 1812, 1814-1820).

${ }^{17}$ El máximo exponente americano fue Francisco Xavier Clavijero, autor de la Historia antigua de México ([1780] 1964). También podemos mencionar a Alzate Ramírez ([1790-1792]1831) y al menos conocido De Cárdenas ([1591] 2003). Véase Gerbi (1982). Un análisis pormenorizado sobre la querella dieciochesca en torno a los alimentos en Europa y América en Bak-Geller (2011).

${ }^{18}$ A partir de la discusión que establece el editor del Nuevo cocinero mexicano a propósito de la obra de Clavijero, en particular sobre las propiedades del chayote, podemos deducir que Galván conocía muy bien la obra del "insigne mejicano y sabio jesuita Clavigero” (Nuevo cocinero mexicano, 1888: 243).
} 
política cuando aparece impreso en las páginas de los primeros libros de cocina nacional. El Nuevo cocinero mexicano ofrece varios ejemplos de cómo las réplicas americanas dirigidas a los eruditos europeos procuraron un valioso material a la causa nacional mexicana, como podemos observar en el rubro correspondiente a la pimienta de Tabasco:

Parece que hay un empeño en desfigurar y confundir el origen de los frutos de este país, que se reputan como propios de otros suelos más dignos, pues [dicen ellos que] el nuestro que hace degenerar a la naturaleza, no es capaz de producir sino abrojos entre los vegetales y seres despreciables y monstruosos en los otros reinos (Nuevo cocinero mexicano, 1888: 645).

América ha dejado de ser el objeto de consideración patriótica y en su lugar se ha impuesto el sabor de lo específicamente mexicano. En esta proyección nacional, la comparación entre los ingredientes americanos y los europeos tiene como único fin ennoblecer la cocina del país. El uso de palabras en lengua náhuatl establece, por otra parte, el origen mexicano de estos productos y su superioridad frente a los de otras partes del mundo. Por ejemplo, según afirma el autor del Nuevo cocinero mexicano, los oceloxochitl (Tigridia pavonia) cultivados por los indios mexicanos reemplazan las castañas de origen europeo (Nuevo cocinero mexicano, 1888: 105); el auauhtle, término que proviene de la palabra "auauhtli", designa a su vez los huevos de un insecto nativo de las lagunas de México que al ser molidos adquieren un sabor muy parecido al del caviar (Nuevo cocinero mexicano, 1888: 47), y qué decir de la apipitzca, ave parecida al "pluvier cendré" de los franceses, en comparación de la cual "la nuestra - señala el mismo autor- es de mayor tamaño" (Nuevo cocinero mexicano, 1888: 35). La lista de elogios a los alimentos mexicanos es extensa y la encabezan el maíz y los platillos confeccionados con este cereal. Del atole se menciona, por ejemplo, que es "un sanísimo y buen alimento de las gentes pobres de nuestro país" y entre sus virtudes se nombra su cualidad "de mantener las fuerzas sin irritar los intestinos y sin causar fatiga al estómago" (Nuevo cocinero mexicano, 1888: 44).

El frijol y el pulque son objeto de este mismo interés por legitimar la naturaleza americana y, en particular, la mexicana. Para ambos casos, la teoría evolucionista antiamericana es reelaborada y usada a favor de los productos nativos de América. El autor del Nuevo cocinero mexicano, después de explicar el rechazo de los europeos hacia los frijoles por la mala calidad que adquirieron en los suelos de aquel continente - "esta legumbre [es] poco usada en Europa a causa de que allá es de mal sabor" (Nuevo cocinero mexicano, 1888: 44)-, exhibe sus cualidades "sabrosas y nutritivas", apreciadas "entre nosotros" (Nuevo cocinero mexicano, 1888: 332), tanto por "los pobres" como por "las casas más decentes". El reconocimiento unánime - "entre nosotros"- que se le otorga a esta legumbre deja en claro la expansión de las fronteras sociales y políticas de la nueva idea de comunidad nacional. También con el objetivo de demarcar los límites de la entidad nacional, aunque esta vez con fines excluyentes, el Cocinero mexicano hace del pulque el punto de partida para establecer una línea de distinción entre un "nosotros" y aquellos que representan una amenaza para la aparente unidad nacional, en este caso los españoles (Anónimo, [1831] 2010: I, 149). El pulque es la bebida que acompaña los "almuerzos nacionales" (Anónimo, [1831] 2010: I, 149) y la que se ha ganado el respeto de los "otros" por sus virtudes curativas y digestivas:

por el largo tiempo que han vivido entre nosotros, [los españoles] ya no le hacen tanto fiero y muchos lo comen con gusto, bebiendo con apetito el pulque, después que han observado que es lo único que les restablece su salud cuando en su edad avanzada son molestados con diarreas que, sin este recurso, los llevaría ciertamente al sepulcro (Anónimo, [1831] 2010: I, 149).

Como muestra el caso del pulque, el editor del Cocinero mexicano introduce los nuevos criterios de 
legitimidad de la cocina mexicana a partir de lo que pareciera a primera vista una contradicción: por una parte, la disociación del elemento español de la definición de mexicano $y$, por otra, la necesidad de validación de los productos nativos por los paladares españoles y europeos. En una edición renovada del Cocinero mexicano, el pulque aparece de nuevo como un producto paradigmático de la cocina nacional, esta vez para demostrar la coherencia y el sentido racional de los hábitos alimenticios locales. El elevado consumo del pulque se explica por la naturaleza misma de la cocina mexicana, que reclama grandes dosis de esta bebida para contrarrestar las altas cantidades de grasa y chile que la caracterizan. Es además el único licor que sienta perfectamente sobre los guisados de chile, principalmente si están cargados de grasa y cebolla cruda, como es costumbre, y parece que la naturaleza siempre próvida lo proporcionó a los mexicanos, que usan el chile en tantas y tan sabrosas preparaciones, sobre las cuales serían dañosísimos el vino de uva y el aguardiente, y aun el agua sobre la que se eleva la grasa mezclada con el chile y causa acedias, indigestiones e incomodidades que se evitan con el pulque (Nuevo cocinero mexicano, 1888: 690-691).

La cocina mexicana es concebida como un sistema coherente en el que el chile, la grasa y el pulque dejan de ser emanaciones de la irracionalidad de los habitantes del país y resultan elecciones lógicas y cuidadosas que satisfacen las necesidades fisiológicas específicas de los mexicanos. ${ }^{19}$ Por otra parte, la oportunidad para desmitificar el gusto europeo, reputado por "delicado", tampoco es desaprovechada por el editor del Cocinero mexicano, sobre todo cuando está en juego el prestigio del chile oriundo del país.

\footnotetext{
${ }^{19}$ La postura relativista del editor del Cocinero mexicano está probablemente vinculada a las ideas del pensador español Jerónimo Feijóo, uno de los autores más leídos en América durante todo el siglo xviII y una buena parte del xIx. Según Feijóo, la diversidad de gustos alimenticios en el mundo depende de las necesidades específicas - naturales y sociales - que pose cada pueblo (Feijóo, [1726-1739] 1779: 229).
}

Entre recetas de chalupas de chile colorado, tortillas enchiladas y envueltos en pipián, el irónico editor señala:

\begin{abstract}
El paladar de los europeos que pasa por delicado no puede soportar el chile, que es reputado entre los más exaltados de ellos como un veneno, pero comen con bastante apetito mil guisos cargados de ajo, mostaza, y, sobre todo, pimienta picantísima que disponen [sus] paladares para sufrir, no ya el chile de nuestro país, sino cuchillos [afilados] (Anónimo, [1831] 2010: I, 149).
\end{abstract}

El chile y el característico picor de la cocina mexicana deben ser preservados de cualquier postura adversaria, en particular de las lecturas mal informadas de los tratados científicos:

Los médicos modernos, habiendo ojeado malamente algunas obras francesas, han declarado la guerra a los estimulantes, principalmente al chile, que según su método nuevamente establecido, debía desaparecer de entre las plantas vivientes. Dios nos libre de sus manos. Amén (Anónimo, [1831] 2010: I, 149).

La "modernidad" de los médicos ignorantes es contrarrestada por la fe católica de los mexicanos, quienes no dudan en evocar a las fuerzas divinas con el fin de salvaguardar el sabor de la nación. En este afán por resguardar la originalidad de la sazón mexicana, el Cocinero mexicano rechaza todas las prácticas alimenticias que no son compatibles con los dogmas del cristianismo, particularmente las "judaizantes". Esta manifestación de "mexicanidad" está expresada con claridad en el capítulo sobre la carne de puerco, en el que el autor alude a los daños que causa esta carne mal cocida, pero sin recurrir a muchos detalles para evitar ser confundido con un judío:

Porque no se diga que judaizamos, no entraremos al examen de los motivos por qué aún en el día y dispersos por todo el mundo rehúsan los judíos comerlo [el puerco], a pesar de no habitar en los climas 
que ocupaban, y donde ciertamente les era dañoso, aunque entre ellos tal vez encontraríamos razones con qué probar que es perjudicial a nuestra salud (Anónimo, [1831] 2010: II, 338).

Catolicismo y comida, conjugados a lo largo del repertorio fundacional de la cocina mexicana, revelan uno de los vínculos más sólidos entre los miembros de la comunidad nacional.

\section{EL ARTE DE LA COCINA SE ESCRIBE EN “MEXICANO"}

Los primeros autores de libros de cocina elaboran uno de los iniciales y más frontales esfuerzos por legitimar la ortografía y las locuciones "mexicanas", tentativa que lleva incluso al editor del Cocinero mexicano a confrontar a la Academia Española de la Lengua:

Aunque no ignoramos la ortografía adoptada últimamente por la Academia española, no hemos creído conveniente conformarnos con ella en los nombres de origen mexicano, como xitomate, nixcomel, etc. [...] Así también adoptamos en nuestra obrita otros nombres de la misma clase [...] aunque no se encuentran, ni deben encontrarse en el diccionario castellano de la misma Academia (Anónimo, [1831] 2010: I, 13).

Es relevante la iniciativa del Cocinero mexicano por legitimar y regularizar los mexicanismos, sobre todo si se considera que su editor se anticipó a la labor emprendida por la Academia Mexicana de la Lengua, instaurada en 1875, casi medio siglo después de la aparición del Cocinero mexicano. Un ejemplo del valor que otorga el autor anónimo del Cocinero mexicano a la lengua vernácula frente a los usos extranjeros del castellano se encuentra en la advertencia publicada en las primeras páginas del recetario:

usamos como masculino el nombre sartén, que es femenino, pero que nadie entre nosotros lo tiene por tal, y el uso general es el director y maestro de la locución (Anónimo, [1831] 2010: prólogo).

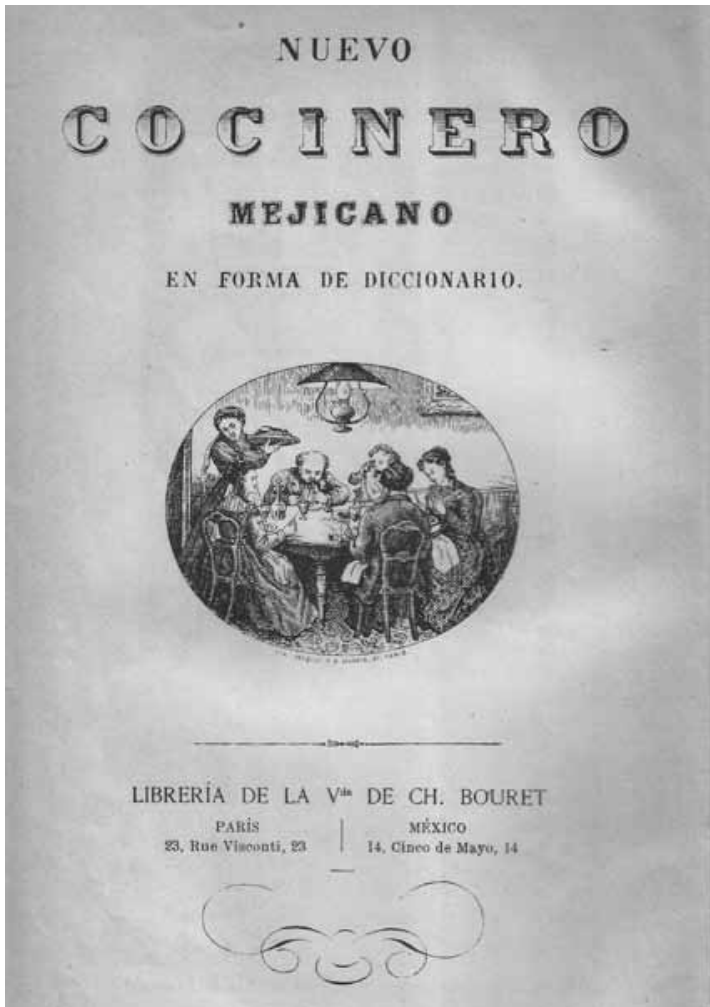

Nuevo cocinero Mejicano en forma de diccionario, México-París, Librería de la Vda. de Ch. Bouret, 1899. Escena de una comida familiar con clara influencia del modelo burgués afrancesado.

En este mismo contexto, las palabras "xitomate" y "mexicano" son escritas al modo característico mexicano, que consiste en aplicar la grafía $x$ en lugar de la $j$ española. ${ }^{20}$ La defensa puede ser más directa, como demuestra el autor del recetario al hacer hincapié, con evidente disgusto, en el hecho de que el Diccionario de la Academia excluía la palabra frijol de la larga lista de nombres con los que se le conoce a esta legumbre:

\footnotetext{
${ }^{20} \mathrm{Si}$ consideramos que la palabra "mexicano" en la receta "jamón a la mexicana" (Anónimo, [1831] 2010) aparece escrita de maneras distintas: con $x$ en el índice y con $j$ en la página 104, hay que imaginar que la ortografía "mexicanista" respondía más a la voluntad nacionalista del editor que a un verdadero uso generalizado de la lengua en México. Cabe señalar que en las ediciones posteriores a 1845 la $j$ vuelve a emplearse en las expresiones "mejicano" y "a la mejicana".
} 
Se conocen los frijoles en castellano con muchos nombres, como alubias, habichuelas, judias, judihuelos, fasoles, frejoles, frisoles y frisuelos; y sólo el de frijoles, con el que llamamos nosotros generalmente a esta legumbre, no se encuentra en el Diccionario de nuestro idioma (Nuevo cocinero mexicano, 1888: 332).

Por otro lado, observamos un interés de los primeros recetarios mexicanos por establecer un sistema de homologación del vocabulario culinario mexicano. La autora del Nuevo y sencillo arte de cocina incluye en su recetario las equivalencias de los diferentes nombres que se emplean en el país para identificar los ingredientes. Por ejemplo, explica que el chile - que ella llama "chile gordo"- posee distintos nombres según las regiones:

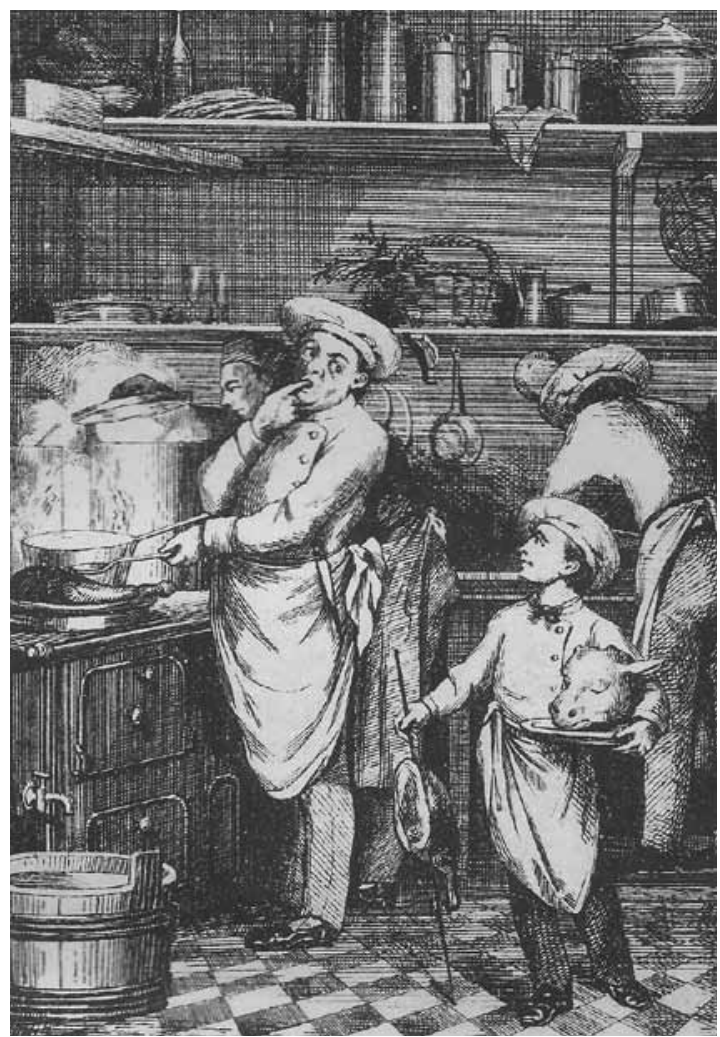

Nuevo cocinero mejicano en forma de diccionario, Librería de la Vda. de Ch. Bouret, 1899, México-París. Sobresale la presencia exclusiva de hombres y el ambiente jerarquizado, propios de la cocina profesional francesa.
Es necesario decir que estos chiles son conocidos con varios nombres. En esta capital son poblanos, y en otros parages [sic] son en unos, chiles verdes grandes, y en otros chiles verdes gordos (Nuevo $y$ sencillo arte de cocina, [1836] 1842: 14).

Del mismo modo, la autora discurre sobre la diversidad taxonómica del chicharrón, que "según los parages [sic] le llaman esponjado, de espuma o duro" (Nuevo y sencillo arte de cocina, [1836] 1842: 118), y también de los frijoles gordos empleados en uno de los guisos del recetario:

Estos frijoles que en esta capital se conocen por ayecotes, en otras poblaciones son conocidos por gordos o patoles (Nuevo y sencillo arte de cocina, [1836] 1842: 157).

En esta misma voluntad de sistematización de los saberes culinarios, el Nuevo y sencillo arte de cocina y el Nuevo cocinero mexicano proponen el nombre genérico de "clemole" para denominar todos los guisos a base de chile que se conocen con diferentes nombres en las regiones del país. La reagrupación de dichos guisos en categorías uniformes y comunes a todos los mexicanos constituye una novedad, como lo explica la autora del Nuevo y sencillo arte de cocina:

Como varios de estos guisados tienen distintos nombres, porque en unos parages [sic] les llaman mole, en otros clemole, en otros tlemole o temole, y en otros chimole, para que en cada uno le den el nombre que acostumbran, advierto que no siendo adobo, manchamanteles, chanfainas, etc., etc., todos los que sean por este estilo [guisos con chile] llevarán por denominación clemole (Nuevo y sencillo arte de cocina, [1836] 1842: 178).

El autor del Nuevo cocinero mexicano resuelve el problema de la gran variedad de nombres para designar los mismos guisos de chile al precisar simplemente que el clemole es un "caldillo de chile con tomates, en que se guisan todas las carnes y legumbres al estilo del país" (Nuevo cocinero mexicano, 1888: 173). 


\section{NUEVA TEMPORALIDAD EN LA NARRATIVA CULINARIA NACIONAL}

Hemos analizado cómo a través de los recetarios se fue construyendo un espacio nacional por medio de la creación de un repertorio de ingredientes y platillos originarios del país y de la organización de un lenguaje culinario común en México. En esta tercera parte exploraremos la forma en que los autores y los editores de los recetarios establecieron su idea de comunidad nacional a partir de una genealogía de sabores que vincula directamente las recetas mexicanas con un origen único y remoto. Este punto cero de la cocina nacional corresponde a la época prehispánica, como puede apreciarse en los títulos de recetas como la del "mole tarasco", la "sopa de Calzonzi" - Caltzontzi era el nombre con el que se designaba a los monarcas del imperio tarasco-, la "ensalada Cuauhtémoc" y la "tápacua indígena" (Torres de Rubio, [1896] 2004), entre otras. En la elección de estos nombres destacan las referencias a una cultura prehispánica en particular: la azteca. Por medio del uso del antiguo náhuatl en los ingredientes y de los títulos de las recetas, los promotores de los recetarios mexicanos las "aztequizan" y establecen una relación directa entre la cocina nacional y la civilización más poderosa de América antes de la llegada de los españoles. En este sentido, cuando los editores utilizan palabras de origen náhuatl, como xoconoxles, quiltoniles, mezclapiques, chicozapote, ahuahutle y guazoncles, éstas aparecen siempre acompañadas por los vocablos "en lengua mexicana". En contraste, los adjetivos que hacen referencia al periodo colonial - "al estilo criollo", "americano", "gachupín" - son limitados. La temporalidad de la cocina mexicana establece una larga continuidad entre el presente y un pasado idílico y procura mantener en silencio los tres siglos de dominio español.

Las cocinas prehispánicas son utilizadas como sinónimos de autenticidad, tradición y prestigio. Sucede lo contrario con la cocina que elaboran los grupos indígenas contemporáneos, que se asocia con "tribus bárbaras" (Nuevo cocinero mexicano, 1888: 172). El caso de los tamales es ilustrativo: en el Nuevo cocinero mexicano se indica que se trata de "un pan sabroso y delicado, que usaban los antiguos pobladores de este continente", que más tarde fue incorporado a la dieta de los descendientes de los españoles (Nuevo cocinero mexicano, 1888: 813). A través de esta imagen "memorializada" del tamal, el autor del recetario formula una de las primeras ideas de tradición en la cocina mexicana. Dicha tradición, no obstante, plantea un conflicto con las prácticas culinarias de los indígenas contemporáneos, como sugiere el autor cuando más adelante recomienda a las lectoras abstenerse de preparar las variedades que consumen los indígenas por ser inadecuados para las "mesas decentes" (Nuevo cocinero mexicano, 1888: 813). Si por "capricho" se desea comerlos, se exhorta a comprarlos a los indios y por ningún motivo prepararlos en la casa (Nuevo cocinero mexicano, 1888: 813). La noción del tiempo histórico en los recetarios nacionales no es cíclica ni acumulativa, sino una nueva manera de ubicar el presente en su relación con el futuro. El pasado ilustre reflejado en los sabores imperiales de la antigüedad convive con un futuro prometedor proyectado a través de títulos de recetas como "a la federación", "republicano", "bella unión” y "del presidente". Los recetarios nacionales marcan el rumbo de la cocina mexicana y a través de él instauran el nuevo tiempo de la nación.

\section{CONCLUSIÓN}

El objetivo de este trabajo ha sido rescatar las prácticas y los discursos sobre cocina y comida del tratamiento anecdótico que generalmente se les otorga. Al desplazar el tema de la cocina de las notas de pie de página hacia los debates centrales de la historiografía nacional, intentamos devolver el lugar que le corresponde a lo culinario como una de las expresiones más novedosas y prevalecientes de la idea nacional en México. A partir de la reconstitución de 


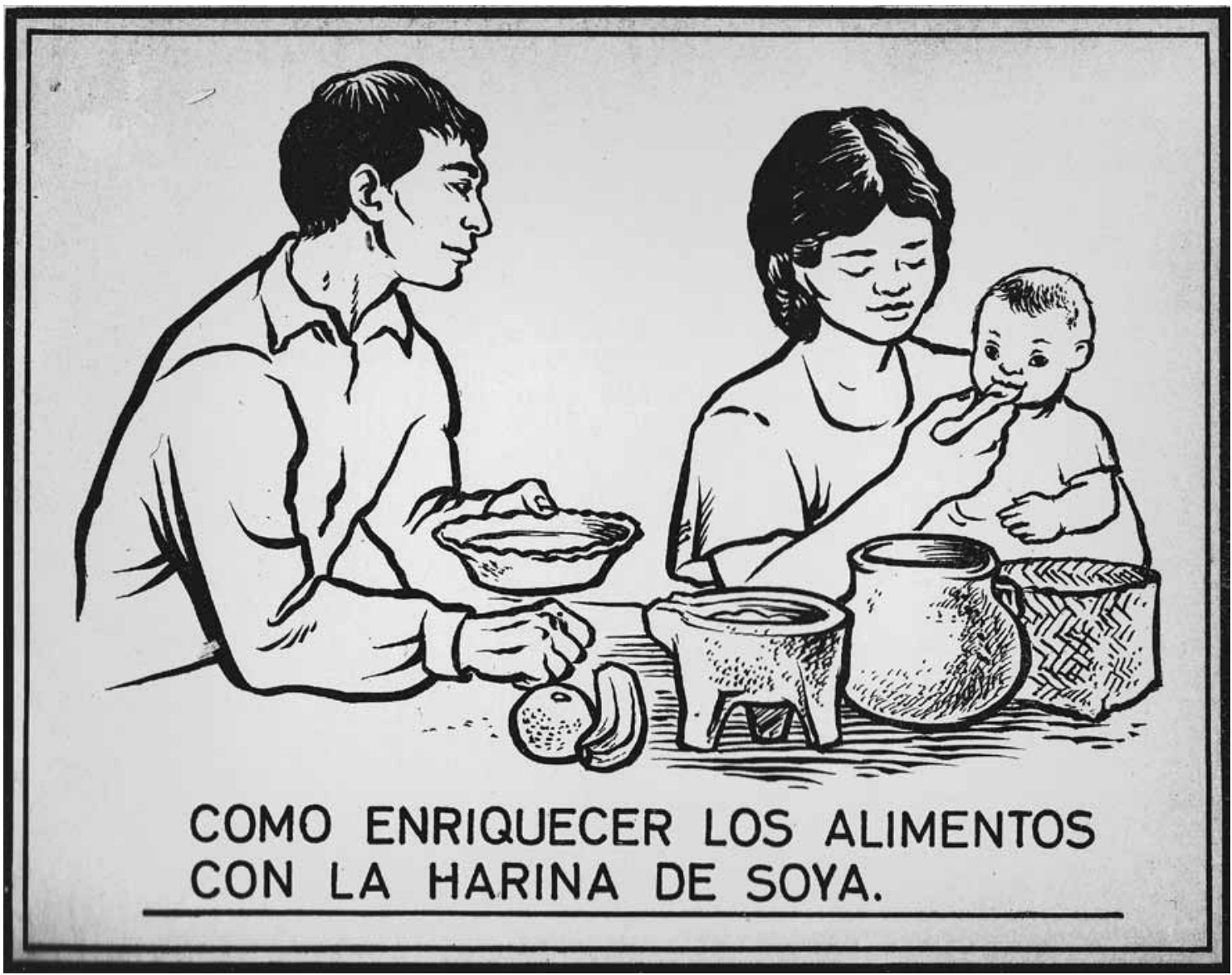

Cómo enriquecer los alimentos con la harina de soya, Departamento de Educación a la Comunidad de la Secretaría de Salubridad y Asistencia, 1964, México.

la experiencia de edición y publicación de recetarios nacionales en México nos propusimos evidenciar la dimensión política de las prácticas y discursos culinarios, y abrir con ello un nuevo espacio para pensar el fenómeno de la nación moderna desde la comida. Los primeros recetarios mexicanos representan una vanguardia en el género editorial del libro de cocina. Más allá de haber puesto al alcance de la sociedad mexicana un nuevo instrumento para aprender a preparar los alimentos, los autores y editores de los primeros recetarios mexicanos fueron pioneros en el proceso de construcción de la idea de nación en México: articularon un lenguaje, una práctica, un espacio y una temporalidad novedosos que permitirían a los lectores apropiarse y reproducir una imagen específica de comunidad nacional. La creación de un repertorio de ingredientes y de platillos distintivos del país; la implementación del principio católico del sabor nacional; la noción de la cocina mexicana como un sistema coherente, racional, efectivo y probado; la formación de un lenguaje culinario nacional, y la fabricación de antecedentes únicos y remotos de la cocina mexicana revelan la originalidad de estos proyectos editoriales que hicieron posible una de las manifestaciones más novedosas, dinámicas y sensoriales de la "mexicanidad". 


\section{BIBLIOGRAFÍA}

Alzate Ramírez, José Antonio [1790-1792] 1831, Gacetas de Literatura de México, reimpresa en la Oficina del Hospital de San Pedro, a cargo del ciudadano Manuel Buen Abad, 4 tomos, Puebla.

Anónimo, [1831] 2010, Cocinero mexicano, o colección de las mejores recetas para guisar al estilo americano, $y$ de las más selectas según el método de las cocinas española, italiana, francesa e inglesa. Con los procedimientos más sencillos para la fabricación de masas, dulces, licores, helados y todo lo necesario para el decente servicio de una buena mesa, Dirección General de Culturas Populares-Consejo Nacional para la Cultura y las Artes, México.

Appadurai, Arjun, 1988, "How to Make a National Cuisine: Cookbooks in Contemporary India”, en Comparative Studies in Society and History, vol. 30, pp. 3-24.

Ayora-Díaz, Steffan Igor, 2012, Foodscapes, Foodfields and Identities in Yucatán, Berghahn Books, Centro de Estudios y Documentación Latinoamericanos (Latin American Studies, núm. 99), Nueva York, Oxford.

Bak-Geller Corona, Sarah, 2008, "Les livres de recettes 'francisés' au Mexique au XIX ${ }^{\mathrm{e}}$ siècle. La construction de la nation et d'un modèle culinaire national', en $\mathrm{An}$ thropology of Food, núm. S4, mayo, en línea: <http:// aof.revues.org/2992>.

_ 2011 , “Des Identités Coloniales à l'Imaginaire Nationale: Cuisine, Société et Politique au Mexique, $\mathrm{XVI}^{\mathrm{e}}$-XIX ${ }^{\mathrm{e}}$ Siècles", tesis de doctorado, L'École des Hautes Études en Sciences Sociales, París.

Bhabha, Homi (ed.), 1990, Nation and Narration, Routledge, Londres, Nueva York.

Blancarte, Roberto (comp.), 1994, Cultura e identidad nacional, Fondo de Cultura Económica, Consejo Nacional para la Cultura y las Artes, México.

Camporesi, Piero, 1981, Le Pain Sauvage. L'Imaginaire de la Faim de la Renaissance au XVIII ${ }^{\mathrm{e}}$ Siècle, Le Chemin Vert, París.

Carantino, Georges, 1999, "Voyage en Pot-au-Feu”, en $\mathrm{Au}$ trement, núm. 187, pp. 35-66.

Cardon, Philippe y Domingo García-Garza (dirs.), 2012, "L'Alimentation dans les Amériques au Prisme des Sciences Sociales", en IdeAs. Idées d'Amériques, vol. 3.

Chatterjee, Partha, 1993, The Nation and its Fragments, Princeton University Press, Princeton.

Clavijero, Francisco Xavier, [1780] 1964, Historia antigua de México, Porrúa, México.

De Cárdenas, Juan, [1591] 2003, Problemas y secretos maravillosos de las Indias, Maxtor, Valladolid, España.
De Pauw, Cornelius, 1768, Recherches Philosophiques sur les Américains, Georges Jacques Decker, Imp. Du Roi, Berlín.

Earle, Rebecca, 2010, "If You Eat Their Food...: Diets and Bodies in Early Colonial Spanish America", en American Historical Review, vol. 115, núm. 3, pp. 688-713.

Feijóo y Montenegro, Benito Jerónimo, [1726-1739] 1779, Teatro crítico universal, tomo 3, Joaquim Ibarra, Impresor de cámara de S. M., Madrid.

Florescano, Enrique, 1991, El nuevo pasado mexicano, Cal y Arena, México.

Gerbi, Antonello, 1982, La disputa del Nuevo Mundo, Fondo de Cultura Económica, México.

Girard, Alain, 1977, "Le Triomphe de 'La Cuisinière Bourgeoise. Livres Culinaires, Cuisine et Société en France aux XVII ${ }^{\mathrm{e}}$ et $\mathrm{XVIII}^{\mathrm{e}}$ Siècles", en Revue d'Histoire Moderne et Contemporaine, t. 24, pp. 497-523.

Hartog, François y Jacques Revel (dirs.), 2001, Les Usages Politiques du Passé, Éditions de l'École des Hautes Études en Sciences Sociales, París.

Hobsbawm, Eric, 1990, Nation and Nationalism since 1780. Programme, Myth, Reality, Cambridge University Press, Cambridge.

Hume, David, 1742, Essays, Moral, Political and Literary, James Clarke editor, Edimburgo.

Juárez López, José Luis, 2008, Nacionalismo culinario. La cocina mexicana en el siglo XIX, Consejo Nacional para la Cultura y las Artes, México. , 2012, Engranaje culinario. La cocina mexicana en el siglo XIX, Dirección General de Culturas PopularesConsejo Nacional para la Cultura y las Artes, México.

Laurioux, Bruno, 1997, Les Livres de Cuisine Médiévaux, Brepols, Turnhout.

Lavallé, Bernard et al., 1991, La Nature Américaine en Débat. Identités, Représentation, Idéologies, Presses Universitaires de Bordeaux, Burdeos.

Leclerc, Georges-Louis, conde de Buffon, 1749-1788, Histoire Naturelle, Générale et Particulière, Imprimerie Royale, París.

Lomnitz, Claudio, 2001, Deep Mexico, Silent Mexico. An Anthropology of Nationalism, University of Minnesota Press, Minneapolis.

Lovera, José Rafael, 1988, Historia de la alimentación en Venezuela, Monte Ávila Editores, Caracas.

Muriel, Josefina y Guadalupe Pérez San Vicente, 2003, "Los hallazgos gastronómicos. Bibliografía de cocina en la Nueva España y el México del siglo xIx”, en Janet Long (coord.), Conquista y comida, Universidad Nacional Autónoma de México, México, pp. 469-479.

Noriega, Cecilia, 1992, El nacionalismo en México, El Colegio de Michoacán, Zamora. 
Notaker, Henry, 2002, “En Contrepoint: L’Identité Nationale à travers les Livres de Cuisine du XIX ${ }^{\mathrm{e}}$ Siècle”, en Martin Bruegel y Bruno Laurioux (dirs.), Histoire et Identités Alimentaires en Europe, Hachette, París, pp. 137-150.

Novísimo arte de cocinar o excelente colección de las mejores recetas para que al menor costo posible, y con la mayor comodidad, pueda guisarse a la española, francesa, italiana, inglesa; sin omitirse cosa alguna de lo que hasta aquí se ha publicado para sazonar al estilo de nuestro país, 1831, impreso en la oficina del C. Alejandro Valdés, México.

Nuevo cocinero mexicano en forma de diccionario, 1888, Librería de Ch. Bouret, París, México.

Nuevo y sencillo arte de cocina, repostería y refrescos dispuesto por una Mexicana, y experimentado por personas inteligentes antes de darse a la prensa, [1836] 1842, Imprenta de Vicente García Torres, México.

Organización de las Naciones Unidas para la Educación, la Ciencia y la Cultura (UNESCO), 2010, "Nomination File no. 00400 for Inscription on the Representative List of the Intangible Cultural Heritage in 2010", Convention for the Safeguarding of the Intangible Cultural Heritage, quinta sesión, Nairobi, en línea: <http://www.unesco. org/culture/ich/doc/download.php?versionID=07344>.

Palti, Elías, 2002, La nación como problema. Los historiadores y la cuestión nacional, Fondo de Cultura Económica (Colección Popular, Serie Breves, núm. 634), Buenos Aires.

Pilcher, Jeffrey, 2000, "Many Chefs in the National Kitchen: Cookbooks and Identity in Nineteenth-Century Mexico", en William H. Beezley y Linda A. Curcio-Nagy (eds.), Latin American Popular Culture: An Introduction, sR Books, Delaware, pp. 123-141.

_ 2001, ;Vivan los tamales! La comida y la construcción de la identidad mexicana, Centro de Investigaciones y Estudios Superiores en Antropología Social, Ediciones de la Reina Roja, Consejo Nacional para la Cultura y las Artes, México.

Raynal, Guillaume y Thomas François, 1770, Histoire Philosophique et Politique des Établissements et du Commerce des Européens dans les Deux Indes, Berry, Ámsterdam.

Simmons, Amelia, 1796, American Cookery, Impresa por Simeon Butler, Hartford.

Simon Palmer, Carmen, 1977, Bibliografía de la gastronomía española, Ediciones Velázquez, Academia Real de Gastronomía, Madrid.

Solares, Laura, 2003, "La aventura editorial de Mariano Galván Rivera. Un empresario del siglo xix”, en Laura Suárez de la Torre (coord.), Constructores de un cambio cultural: impresores-editores y libreros en la Ciudad de México, 1830-1855, Instituto de Investigaciones Históricas “Dr. José María Luis Mora”, México, pp. 27-99.

Torres de Rubio, Vicenta, [1896] 2004, Manual de cocina michoacana, Gobierno del Estado de Michoacán, Fundación Herdez, Universidad Michoacana de San Nicolás de Hidalgo, México.

Toussaint-Samat, Maguelonne, 2001, Histoire de la Cuisine Bourgeoise, du Moyen Âge à Nos Jours, Albin Michel, París.

Voltaire, 1994, Candide, ou l'Optimisme, Du Chêne, París. von Humboldt, Alexander, 1812, Atlas Géographique et Physique du Royaume de la Nouvelle-Espagne, F. Schoell, París.

, 1814-1820, Le Voyage aux Régions Équinoxiales du Nouveau Continent, Fait en 1799-1804, vol. 6, F. Schoell, París.

Willian, Anne, 2012, The Cookbook Library. Four Centuries of the Cooks, Writers, and Recipes that Made the Modern Cookbook, University of California Press, Berkeley, Los Ángeles, Londres. 